\title{
INOVASI PEMBELAJARAN PENDIDIKAN AGAMA ISLAM DI ERA INFORMATION AND COMMUNICATION TECHNOLOGY
}

\author{
Ummul Jazilah \\ Prodi Pendidikan Agama Islam, UIN Sunan Ampel Surabaya \\ e-mail: ummuljazilah@gmail.com
}

\begin{abstract}
Digital era is a condition where everyone is able to access various informations on the network (online). It is available in cyberspace and make easier to access everything without space and time limitation. There is no world block after the invention of this system. The digital natives, has a tendency to search information through internet. They prefer to get advantage of smartphone features or other technological devices for entertainment or to fulfill primary needs. Music and movies can be enjoyed or downloaded freely or paid cheaply. For scientific needs and accessing information, one can get articles freely without any requirements in this digital era. This phenonema on the other hand is an encouraging thing that indicates a change of the world in a more advanced. This era has demanded learning innovation, and technological advances must be utilized as best as possible by educators, especially Islamic religious educators. Utilization of technology in the learning process is a must so that the learning process is not stagnant and rigid. Utilization or innovation of Islamic religious education learning must be carried out immediately, especially in the learning method. The internet as a learning media can be an alternative method of learning Islamic religious education. This can be in the form of elearning, or applications which facilitate the learning material delivery, resulted learning process is more interesting.
\end{abstract}

Keywords: innovation, learning, Islamic religious education, information and communication technology

\section{PENDAHULUAN}

Perkembangan teknologi informasi dan komunikasi semakin pesat diera globalisasi saat ini. Teknologi informasi dan komunikasi telah membawa perubahan dalam berbagai aspek kehidupan manusia, termasuk dalam bidang pendidikan. Kemajuan teknologi informasi dan komunikasi telah banyak membantu dan mempermudah aktifitas dalam pelaksanaan pendidikan, baik bagi para pendidik, peserta didik maupun penyelenggara pendidikan. Hal ini didukung dengan munculnya berbagai produk teknologi yang dapat digunakan sebagai media dan sumber pembelajaran. Penggunaan teknologi sebagai media dan sumber pembelajaran merupakan alternatif yang tepat untuk pengembangan pelaksanaan proses pembelajaran. 
Beberapa hasil penelitian menunjukkan bahwa efektifitas pembelajaran dengan menggunakan teknologi lebih baik berbanding dengan pembelajaran tradisional atau konvensional. Hasil penelitian Rusman tahun 2006 menunjukkan hasil belajar dengan menggunakan pembelajaran berbasis komputer model tutorial dan drill and practice jauh lebih baik daripada pembelajaran konvensional. Wilfrid Laurier tahun 1998 juga menghasilkan penelitian bahwa mahasiswa yang menggunakan Web dalam pembelajaran terbukti dua kali lebih cepat waktu belajarnya dibanding mahasiswa klasikal, 80\% mahasiswa tersebut berprestasi baik dan amat baik, serta 66\% dari mereka tidak memerlukan bahan cetak. ${ }^{1}$

Kurikulum Pendidikan Agama Islam juga telah menekankan pentingnya penggunaan teknologi dalam proses pembelajaran. Teknologi diperlukan dalam mewujudkan kreativitas dan keterampilan peserta didik serta untuk mendapatkan informasi terbaru dalam rangka mencari gagasan untuk perancangan dan pembuatan benda-benda keterampilan sebagai wujud dari kreativitas peserta didik. ${ }^{2}$

Penggunaan teknologi informasidan komunikasi dalam pembelajaran sangat tergantung kepada kesediaan guru untuk menggunakannya dalam program pembelajaran serta kemampuan guru dalam menggunakan teknologi tersebut sebagai media dan sumber pembelajaran yang efektif. Oleh karena itu, setiap guru harus senantiasa bersedia untuk menghadapi tantangan teknologi informasidan komunikasi yang semakin maju dan mempunyai komitmen untuk senantiasa menggunakan teknologi informasi dan komunikasi dalam pembelajaran. Sehubungan dengan hal ini, penulis ingin menguraikan penggunaan teknologi informasi dan komunikasidalam pembelajaran Pendidikan Agama Islam. Dengan digunakannya teknologi informasidan komunikasi ini oleh para guru Pendidikan Agama Islam, diharapkan dapat membantu dan mempermudahmerekauntuk mengarahkan peserta didik dalam mencapai tujuan pembelajaran.

1 Rusman, dkk, Pembelajaran Berbasis Teknologi Informasi dan Komunikasi, (Jakarta: Rajawali Pers, 2012), 2

2 Depdiknas, Kurikulum 2004 Pendidikan Agama Islam Sekolah Menengah Atas dan Madrasah Aliyah, (Jakarta: Balitbang Depdiknas, 2003), 15 


\section{PEMBAHASAN}

\section{A. Teknologi Pendidikan Sebagai Teori dan Praktik}

Teknologi pendidikan dalam istilah bahasa Inggris InstructionalTechnology adalah media komunikasi yang berkembang pesat, dandapat dimanfaatkan dalam pendidikan. Pendapat lain mengatakanbahwa teknologi pendidikan adalah pengembangan, penerapan danpenilaian sistem-sistem, teknik dan alat bantu untuk memperbaiki danmeningkatkan proses belajar manusia. ${ }^{3}$

Teknologi pendidikandiartikan sebagai cara mendesain sistematis, melaksanakan danmengevaluasi keseluruhan proses belajar-mengajar, hubungan dengantujuan-tujuan yang telah dikhususkan serta didasarkan atas prinsipprinsipbelajar dan komunikasi yang terjadi pada manusia, dan memanfaatkan pelbagai sumber manusia dan non manusia denganmaksud agar pengajaran lebih efektif. ${ }^{4}$

Definisi teknologi pendidikan perlu dilihat dari berbagai aspek yaitu: aspek teoritik, aspek bidang garapan dan aspek profesi. Jika dipandang dari aspek teoritik, teknologi pendidikan adalah serangkaian ide dan prinsip tentang cara bagaimana pendidikan dan pembelajaran harus dilaksanakan dengan menggunakan teknologi. Sedangkan aspek bidang garapan memandang teknologi pendidikan sebagai aplikasi ide-ide dan prinsip-prinsip teoritik untuk memecahkan masalah-masalah konkrit dalam bidang pendidikan dan pembelajaran. Serta dari aspek profesi, teknologi pendidikan dipandang sebagai profesi suatu kelompok pelaksana tertentu yang diorganisasikan, memenuhi kriteria tertentu, memiliki tugas tertentu, dan bergabung untuk membentuk bagian tertentu dari bidang tersebut. $^{5}$

Makna teknologi pendidikan sebagai bidang garapan, paling sedikit meliputi tiga hal, yaitu tumbuh dan berkembangnya sistempembelajaran yang inovatif, penggunaan teknologi komunikasi dan informasi, serta teknologi pembelajaran untuk pengembangan SDM. Makna teknologi pendidikan sebagai

\footnotetext{
${ }^{3}$ S. Nasution, Teknologi Pendidikan (Jakarta: Bumi Aksara, 2005), 1.

${ }^{4}$ Nana Sudjana dan Ahmad Rivai, Teknologi Pengajaran (Bandung: Sinar Baru, 1989), 68.

${ }_{5}^{5}$ ECT, Definisi Teknologi Pendidikan, Satuan Tugas Definisi dan Terminologi AECT. Terj. Yusufhadi Miarso, et.al. (Jakarta: Rajawali, 1977), 19-20
} 
profesi berkembang ke arah peningkatan keahlian, pengakuan keprofesian dan berkembangnya organisasi profesi. Sedangkan makna teknologi pendidikan sebagai bidang kajian telah berkembang dengan tiga pendekatan, yaitu: pendekatan empirik, pendekatan analitik, dan pendekatan teoritik. ${ }^{6}$

Pada aspek bidang garapan ini yaitu adanya sistem pembelajaranberbasis teknologi atau pemanfaatan teknologi untuk pembelajaran bisa memberikan kontribusi kepada peningkatan kualitas pembelajaran pendidikan agama Islam.

Pada aspek kajian, teknologi pendidikan dimaknai sebagai pendekatanpendekatan yang dapat memberikan beberapa alternatif metode pemecahan masalah (problem-solving-method) dalam pembelajaran. Secara garis besarnya, langkah-langkah yang perlu ditempuh dalam pendekatan teknologi pendidikan ini adalah: 1)merumuskan tujuan jelas, harus dicapai, dan dapat dipandang sebagai masalah; 2) menyajikan hipotesis; 3) menilai hasil pelajaran/hipotesis; 4) mencari perbaikan (revisi), jika hasilnya belum memenuhi syarat atau standar yang telah ditentukan. ${ }^{7}$ Melihat langkah-langkah tersebut dapat digambarkan bahwa teknologi dalam arti pendekatan bisa disama artikan dengan langkah-langkah dalam metode penelitian karena setiap pembelajaran dimulai atas dasar problem atau permasalahan, dan teknologi membantu memberikan keefektifan untuk mendeteksi serta memecahkan problem dalam proses pembelajaran.

Beberapa makna teknologi pendidikan di atas telah melalui beberapa tahapan atau paradigma. Sekilas di bawah ini dipaparkan histori pemaknaan teknologi pendidikan yang diawali sekitar tahun 70-an, teknologi pendidikan selalu dikaitkan dengan adanya peralatan terutama yang berupa ruparungu (audiovisual). Makna ini disebut sebagai paradigma pertama. Paradigma kedua, bertolak dari pendekatan sistem dan teori komunikasi dalam kegiatan pendidikan. Paradigma ketiga, bertolak dari pendekatan manajemen proses instruksional, dimana unsurunsur memiliki fungsi yang berbeda tapi dijalin secara integral. Paradigma keempat bertolak dari pendekatan ilmu prilaku yaitu memfokuskan perhatian kepada diri peserta didik agar mereka dapat dimungkinkan untuk belajar secara efektif dan efisien. Paradigma baru atau paradigma kelima memaknai fokus

${ }^{6}$ Yusufhadi Miarso, Menyemai Benih Teknologi Pendidikan (Jakarta: Kencana, 2007), 560-563

${ }^{7}$ Nasution, Teknologi Pendidikan, 9. 
Teknologi pendidikan adalah memecahkan masalah belajar. Maka definisi teknologi pendidikan adalah teori dan praktik dalammerancang, mengembangkan, memanfaatkan, mengelola, dan menilai proses dan sumber untuk belajar. ${ }^{8}$ Teknologi memiliki karakteristik tertentu yang sangat relevan bagi kepentingan pendidikan. Teknologi pendidikan memungkinkan adanya: Pertama, penyebaran informasi secara luas, merata, cepat, seragam dan terintegrasi. Kedua, penyajian materi secara logis, ilmiah dan sistematis serta mampu melengkapi, menunjang, memperjelas konsep-konsep, prinsip-prinsip atau proposisi materi pelajaran. Ketiga,menjadi partner guru dalam rangka mewujudkan proses belajar mengajar secara efektif, efisien dan produktif sesuai kebutuhan dan tuntutan peserta didik. Keempat, pemanfaatan sebagai sumber belajar,dapat menyajikan materi secara lebih menarik. ${ }^{9}$

\section{B. Model-model Pembelajaran Berbasis ICT}

Terdapat banyak sekali model ICT yang dapat diterapkan dalam proses bembelajaran. Menurut Rusman, model-model tersebut. ${ }^{10}$ Pertama Model Drillsadalah suatu model dalam pembelajaran dengan jalan melatih siswa terhadap bahan pelajaran yang sudah diberikan. Melalui model ini akan ditanamkan kebiasaaan tertentu dalam bentuk latihan. Latihan terus menerus menjadikan pelajaran akan tertanam kemudian menjadi kebiasaan.

Model ini bertujuan memberikan pengalaman belajar yang konkret melalui penciptaan tiruan-tiruan bentuk pengalaman yang mendekati suasana sebenarnya. Program pembelajaran berbasis komputer merupakan program pembelajaran yang digunakan dalam proses pembelajaran dengan menggunakan software komputer yang berisi materi pelajaran dalam bentuk latihan-latihan.

Hal di atas sejalan dengan pendapat Robert Heinich, Molenda, dan James D. Russel bahwa: "computer system can delivery instruction by allowing them to interact with the lesson programed into the system" (sistem komputer dapat menyampaikan

${ }^{8}$ Miarso, Menyemai Benih, 544

${ }^{9}$ Sudarwan Danim, Media Komunikasi Pendidikan: Pelayanan Profesional Pembelajaran dan Mutu Hasil Belajar (Jakarta: Bumi Aksara, 1994), 3-4

${ }^{10}$ Rusman, Model-model Pembelajaran; Mengembangkan Profesionalisme Guru, (Jakarta: Raja Grafindo Persada, 2013), 290-320 
pembelajaran secara individual dan langsung kepada para siswa dengan cara berinteraksi dengan mata pelajaran yang diprogramkan ke dalam sistem komputer).

Kedua Model Tutorial,pada dasarnya sama dengan program bimbingan yang bertujuan memberikan bantuan kepada siswa agar dapat mencapai hasil belajar secara optimal. Kegiatan ini dibutuhkan sebab siswa yang dibimbing melaksanakan kegiatan belajar mandiri yang bersumber dari modul-modul dalam bidang studi tertentu.

Benang merah pembelajaran tutorial adalah untuk memberikan kepuasan atau pemahaman secara tuntas (mastery learning) kepada siswa mengenai materi/bahan pelajaran yang sedang dipelajari. Adapun yang menjadi identitas dari tutorial adalah pengenalan, penyajian informasi, pertanyaan dan respon jawaban, penilaian respon, pemberian umpan balik tentang respon, pembetulan, segmen pengaturan pembelajaran, dan penutup.

Komputer sebagai tutor berorientasi pada upaya dalam membangun perilaku siswa melalui penggunaan komputer. Secara sederhana pola pengoperasiannya sebagai berikut: a) komputer menyajikan materi, b) siswa memberikan respon, c) respon siswa dievaluasi oleh komputer dengan orientasi pada arah siswa dalam menempuh prestasi berikutnya, dan d) melanjutkan atau mengulangi tahapan sebelumnya.

Ketiga Model Simulasi yang merupakan salah satu strategi pembelajaran yang bertujuan memberikan pengalaman belajar yang lebih konkret melalui penciptaan tiruan-tiruan bentuk pengalaman yang mendekati suasana sebenarnya dan berlangsung dalam suasana yang tanpa risiko. Model simulasi adalah model CBI yang menampilkan materi pelajaran yang dikemas dalam bentuk simulasisimulasi pembelajaran dalam bentuk animasi yang menjelaskan konten secara menarik, hidup, dan memadukan unsur teks, gambar, audio, gerak, dan paduan warna yang serasi dan harmonis.

Secara umum tahapan produksi model simulasi adalah: a) perencanaan produksi model simulasi (RPP model simulasi, program PBK simulasi, flowchart PBK model simulasi), dan b) proses produksi program simulasi, terdiri dari pendahuluan (introduction) dan penyajian informasi (presentation of information). 
Keempat Model Instructional Games yangmerupakan bentuk metode pembelajaran berbasis komputer. Tujuan model ini adalah menyediakan pengalaman belajar yang memberikan fasilitas belajar untuk menambah kemampuan siswa melalui bentuk permainan yang mendidik. Instructional games tidak perlu menirukan realita, namun dapat memiliki karakter yang menyediakan tantangan yang menyenangkan bagi siswa.

Karakteristik instructional games terlihat dari tahapan yang harus ditempuh dalam pembuatan instructional games sebagai model pembelajaran, yaitu tujuan, aturan, kompetisi, tantangan, khayalan, keamanan, dan hiburan. Adapun komponen instructional games terbagi menjadi tiga, meliputi pendahuluan (introduction), bentuk instructional games (body of instructional games), dan penutup (closing).

\section{Prinsip-prinsip Pembelajaran Berbasis ICT}

ICT merupakan salah satu model pembelajaran yang mensyaratkan adanya berbagai jenis media pembelajaran. Sehingga diperlukan berbagai pertimbangan dalam memilih media yang cocok untuk penerapan ICT. Menurut Arief S. Sadiman, dkk, beberapa faktor yang perlu dipertimbangkan antara lain: 1) Tujuan instruksional yang ingin dicapai, 2) Karakteristik siswa atau sasaran; 3) Jenis rangsangan belajar yang diinginkan (audio, visual, gerak, dan seterusnya), 4) Keadaan latar atau lingkungan, 5) Kondisi setempat; dan 6) Luasnya jangkauan yang ingin dilayani. ${ }^{11}$

ICT dalam beberapa aspek sangat membutuhkan keberadaan internet. Sebagai dasar memanfaatkan jaringan internet sebagai pendukung ICT, maka beberapa hal yang perlu mendapatkan perhatian yaitu: 1) Faktor lingkungan, meliputi institusi penyelenggara pendidikan dan masyarakat; 2) Siswa atau peserta didik, meliputi usia, latar belakang, budaya, penguasaan bahasa, dan gaya belajar; 3) Guru atau pendidik, meliputi latar belakang, usia, gaya mengajar, pengalaman, dan personaliti; 4) Faktor teknologi, meliputi komputer, perangkat lunak, jaringan,

${ }^{11}$ Arief S. Sadiman, dkk, Media Pendidikan; Pengertian, Pengembangan, dan Pemanfaatannya, (Jakarta: Raja Grafindo Persada, 2012), 84. 
koneksi internet, dan berbagai kemampuan yang dibutuhkan dalam penerapan internet di lingkungan sekolah. ${ }^{12}$

Adapun prinsip-prinsip umum dalam penggunaan teknologi, dalam hal ini ICT perlu mengedepankan prinsip-prinsip sebagai berikut:1) Efektif dan efisien. Penggunaan ICT perlu memperhatikan manfaat dari teknologi ini dalam hal mengefektifkan belajar, meliputi pemerolehan ilmu, kemudahan dan keterjangkauan, baik waktu maupun biaya; 2) Optimal. Melalui penggunaan ICT setidaknya pembelajaran menjadi bernilai "lebih" daripada tanpa menggunakannya. Nilai lebih yang diberikan ICT adalah keluasan cakupan, kekinian (up to date), kemodernan, dan keterbukaan; 3) Menarik. Artinya dalam prinsip ini, pembelajaran di kelas akan lebih menarik dan memancing keingintahuan yang lebih. Pembelajaran yang tidak menarik dan memancing keingintahuan yang lebih akan berjalan membosankan dan kontra produktif untuk pembelajaran; 4) Merangsang daya kreativitas berpikir pelajar. Dengan menggunakan ICT tentu saja diharapkan pelajar mampu menumbuhkan kreativitasnya dengan maksimal yang terdapat di dalam diri mereka. Seorang anak yang mempunyai kreativitas tinggi tentunya berbeda dengan pelajar yang mempunyai kreativitas rendah. Pelajar yang mempunyai kreativitas tinggi, tentu akan mampu menyelesaikan permasalahan dengan cepat dan tanggap terhadap permasalahan yang muncul dan mampu berpikir solutif secara cepat. ${ }^{13}$

Dengan demikian, dapat dipahami prinsip-prinsip ICT merupakan jembatan untuk mencapai tujuan pendidikan itu sendiri ketika digunakan dalam pembelajaran. Penggunaan ICT tidak justru menjadi penghambat dalam pembelajaran, namun akan memberikan manfaat dan nilai lebih dalam mencapai tujuan pembelajaran.

\section{ANALISIS}

\section{A. Aplikasi ICT dalam Pembelajaran PAI}

Islam sebagai sebuah agama yang penuh rahmat senantiasa mengandung ajaran yang mampu disesuaikan dengan kondisi dan perkembangan

\footnotetext{
${ }^{12}$ Udin Saefudin Sa’ud, Inovasi Pendidikan, (Bandung: Alfabeta, 2008), 190-191.

${ }^{13} \mathrm{Hafidz}$, Pengembangan Pembelajaran PAI Berbasis IT dalam https: // rachmat fatahillah .blogspot.com/2014/ 04/ pengembangan-pembelajaran-pai-berbasis.html. (Diakses 13 Juli 2018)
} 
zaman. Termasuk dalam hal pemanfaatan teknologi, Islam secara substantif mendukung dan mengakomodir pemanfaatan teknologi, utamanya dalam dunia pendidikan.

Fenomena yang ada di langit dan di bumi tidak hanya dilihat saja tetapi perlu dicermati, dipelajari, dikaji, dan diteliti untuk dikembangkanmenjadi Ilmu Pengetahuan dan Teknologi (IPTEK). Umat manusia hendaknya mengambil manfaat dari tanda-tanda kebesaran Allah dan mengambil peringatan (tazkir) yang disampaikan para utusan Allah. Munculnya ICT dalam dunia pendidikan terinspirasi dari kemajuan teknologi informasi dan komunikasi yang merupakan salah satu tanda-tanda kebesaran Allah Swt.

Dalam konteks pembelajaran Pendidikan Agama Islam (PAI), ICT memberikan banyak pilihan kepada para guru. Misalnya e-dukasinet (pembelajaran berbasis internet), penggunaan telematika, e-learning, blog, multimedia resources center, teknologi pembelajaran melalui komik, dan video conference. Namun, setiap pilihan membawa konsekuensi tersendiri, karena saling berhubungan dengan sarana sekolah/madrasah, termasuk yang dimiliki sendiri oleh guru PAI. Secara umum, menurut Yayu Susanti jenis bahan ajar yang dapat dipilih adalah:1) Bahan ajar pandang (visual) terdiri atas: a) bahan cetak (printed) seperti handout, buku, modul, lembar kerja siswa, brosur, leaflet, wallchart, foto/gambar, dan b) non cetak (non printed), seperti model/maket. 2) Bahan ajar dengar (audio) seperti kaset, radio, piringan hitam, dan compact disk audio, 3) Bahan ajar pandang dengar (audio visual) seperti video compact disk dan film, 4) Bahan ajar multimedia interaktif (interactive teaching material) seperti CAI (Computer Assisted Instruction), compact disk (CD) multimedia pembelajaran interaktif, dan bahan ajar berbasis web (web based .$^{14}$

Dari uraian di atas, maka perlu dirumuskan Rencana Strategis (Renstra) dalam pemanfaatan ICT menuju hasil pembelajaran PAI yang berkualitas. Strategi tersebut dapat dijabarkan sebagai berikut: 1) Penyusunan dan pelaksanaan instrumen pembelajaran PAI (silabus, RPP, modul bahan ajar,

${ }^{14}$ Yayu Susanti, Pembelajaran PAI Berbasis Internet dalam http: // yayususanti.blogspot.com /2016/01/ pembelajaran-pai-berbasis-internet_17.html. (Diakses 13 Juli 2018) 
sistem, dan analisis instrumen penilaian). Kemudian, semua instrumen tersebut diinput ke dalam komputer; 2) Pemilihan media ICT yang sesuai dengan kondisi dan karakterisitik sekolah yang meliputi bahan ajar pandang (visual); bahan ajar dengar (audio); bahan ajar pandang dengar (audio visual); ataukah bahan ajar multimedia interaktif (interactive teaching materials). ${ }^{15}$

Sebenarnya di dalam tataran implementasi, jika melihat kondisi nyata di lapangan, sudah banyak guru PAI yang menguasai ICT, tetapi belum dimaksimalkan. Secara sederhana bentuk praktek ICT dalam pembelajaran PAI dapat digambarkan melalui kegiatan berikut: 1) Penggunaan program powerpoint dalam proses pembelajaran PAI di kelas. Melalui program tersebut, guru tinggal menulis poin-poin penting materi yang akan disampaikan. Agar lebih menarik, bisa juga guru menggunakan program macromedia flash, 2) Penggunaan e-mail untuk mengumpulkan tugas dari peserta didik. Sekarang ini yang biasa dilakukan guru kepada peserta didik dalam mengumpulkan tugas melalui buku atau kertas. Pengumpulan tugas melalui e-mail sekaligus mendidik kepada peserta didik untuk mengurangi global warming (pemanasan global), 3) Penggunaan mailing list (atau grup WA) untuk diskusi kelas yang diajarkan. Melalui mailing list guru dapat membuat grup atau kelompok sendiri, bisa berupa satu kelas atau satu sekolah untuk berkomunikasi. Di sini guru PAI menginformasikan materi pembelajaran yang akan disampaikan pada pertemuan ke depan via mailing list. Sedangkan seluruh anggota grup akan mengetahuinya dalam waktu yang bersamaan. 4) Penggunaan web blog untuk pembelajaran di dalam atau luar kelas. Ketika disebut web blog, banyak guru yang bertanya-tanya pasti mahal biayanya. Memang untuk website yang komersial, pengguna (user) harus membayar sesuai dengan tarif, tetapi untuk web blog, pengguna tidak harus membayar alias gratis, seperti wordpress dan blogspot. Melalui web blog guru dapat menampilkan semua karya atau hasil pemikiran yang dimiliki. ${ }^{16}$

Dari keempat penggunaan ICT dalam pembelajaran di atas, apabila dilakukan oleh guru PAI, maka akan berdampak positif pada ketertarikan peserta

${ }^{15}$ Yayu Susanti, Pembelajaran P AI Berbasis., (Diakses 13 Juli 2018)

16 Hery Nugroho, Pembelajaran PAI Berbasis ICT dalam ttps: // herynugrohoyes. Wordpress .com/2012/08/11/pembelajaran-pai-berbasis-ict /. (Diakses 13 Juli 2018) 
didik terhadap mata pelajaran PAI di sekolah. Sehingga peserta didik dalam mengikuti mata pelajaran PAI tidak terpaksa, melainkan kesadaran dari diri sendiri, sehingga pembelajaran menjadi bermakna.

\section{B. Inovasi Pembelajaran PAI di Sekolah}

Inovasi adalah suatu perubahan baru menuju ke arah perbaikanatau berbeda dari yang ada sebelumnya, dilakukan dengan sengajadan berencana. Dalam konteks teknologi pembelajaran, inovasimengacu kepada pemanfaatan teknologi canggih, baik perangkatlunak (software) maupun perangkat keras (hardware) dalam prosespembelajaran. Tujuan utama aplikasi teknologi baru ini adalah untukmeningkatkan mutu, efektivitas dan efisiensi pembalajaran. Metode dan strategi juga merupakan sebuah inovasi dalam pembelajaran. ${ }^{17}$ Inovasi dalam hal pesanpesan al-Qur'an Hadis yang disampaikandalam pembelajaran PAI telah mengalami kemajuan. Hal ini terbuktidengan banyaknya software-software Islami yang diciptakan oleh pakaryang bisa dimanfaatkan dalam menunjang media pembelajaran.Seperti halnya power point, flash, al-Qur'an digital, Hadits digital, ebook, games dan lain sebagainya. Dengan demikian pemanfaatan ICT, bisamembawa dampak positif bagi pembelajaran PAI. Ia bisamempermudah pembelajaran, sekaligus bisa menampilkanpembelajaran yang tidak membosankan dengan hanya bertumpu padasatu metode saja. Guru PAI juga tidak dipandang ketinggalan zaman,namun bisa mempelopori ICT yang bermoral dan bermartabat. $36{ }^{18}$ menambah wawasan berkaitan dengan mata pelajaran alQur'anHadis, dengan tetap mengikuti bentuk pembelajaran Web EnhanceCourse yang menjadikan internet sebagai penunjang kegiatan belajarmengajar di kelas semata.Inovasi juga dapat dilakukan dengan dua pendekatan yangberbeda, bisa diawali dengan pendekatan topik terlebih dahulu ataudiawali dengan pendekatan teknologi.

Dalam pembelajaran al-Qur'anHadis misalnya diawali dengan menentukan topik atau materi yangakan dipelajari peserta didik, misalnya materi tajwid dengan judul"Hukum nun sukun dan tanwin", lalu guru mencari

\footnotetext{
${ }^{17}$ Bambang Warsita, Teknologi Pembelajaran, Landasan dan Aplikasinya (Jakarta: Rineka Cipta, 2008), 295

${ }^{18}$ Goze Isno. "Pembelajaran PAI Berbasis ICT", dalam http://isnoe82.blogspot.com. diakses 10 Desember 2011.
} 
ataumemanfaatkan teknologi yang relevan berupa sofware atau aplikasiyang memuat materi tersebut. Sekarang sudah dapat didownloadberbagai macam aplikasi bisa berupa permainan/games tentangmateri-materi PAI.Berikut langkahlangkah inovasi pembelajaran al-Qur'an Hadisberbasis ICT (pemanfaatan web blog dan media games dalampembelajaran):1) Mengajarkan materi al-Qur'an Hadits tentang ilmu tajwid denganmemanfaatkan web blog di internet yang menjelaskan tentanghukum nun mati dan tanwin, 2) Memberikan kesempatan kepada setiap peserta didik untukmenampilkan web blog mereka serta menjelaskan materi yang telahmereka susun sesuai silabus di depan peserta didik yang lain, 3) Memberikan kesempatan peserta didik lain untuk bertanya denganmemanfaatkan fasilitas komentar di dalam web blog yang telahditampilkan ataupun bertanya secara langsung, 4) Guru memberikan kesempatan kepada peserta didik untuk mendownloadgames tentang ilmu tajwid di playstore, lalu guru menunjukpeserta didik untuk mencoba games tersebut dengan menjawabpertanyaan-pertanyaan yang ada di dalam games, 5) Guru memberikan penjelasan secara detail tentang materi tersebut,melengkapi jawaban dengan menggunakan media web blog, serta menilai hasil jawaban peserta didik dalam media games.

\section{KESIMPULAN}

Teknologi pendidikan dapat diartikan sebagai teori dan praktikdalam merancang, mengembangkan, memanfaatkan, mengelola, danmenilai proses dan sumber untuk belajar. Internet merupakan salahsatu media yang relevan jika dimanfaatkan demi menunjang mutupendidikan agama Islam. Karena dapat memberikan kemudahan dankecepatan dalam menyampaikan informasi sehingga prosespembelajaran PAI dapat berjalan secara efektif dan efisien. Internetdapat memberikan beberapa fasilitas serta layanan/aplikasi seperti:web blog, email, e-learning, dan lain-lain untuk dimanfaatkan dalamproses pembelajaran PAI di sekolah maupun madrasah.Pembelajaran PAI berbasis information and communication technology (ICT) dapat menjadi solusi bagi guru PAI yang selama ini mengalamikesulitan dan stagnanasi dalam proses pembelajaran terutama aspekmetode pembelajaran. 


\section{DAFTAR PUSTAKA}

AECT, Definisi Teknologi Pendidikan, Satuan Tugas Definisi dan Terminologi AECT. Terj.Yusufhadi Miarso, et.al. Jakarta: Rajawali, 1977.

Arief S. Sadiman, dkk, Media Pendidikan; Pengertian, Pengembangan, dan pemanfaatannyaJakarta: Raja Grafindo Persada, 2012

Bambang Warsita, Teknologi Pembelajaran, Landasan dan Aplikasinya Jakarta: Rineka Cipta, 2008

Depdiknas, Kurikulum 2004 Pendidikan Agama Islam Sekolah Menengah Atas dan Madrasah Aliyah, Jakarta: Balitbang Depdiknas, 2003

Hafidz, Pengembangan Pembelajaran PAI Berbasis IT dalam https://rachmatfatahillah.blogspot.com/2014/04/pengembangan pembelajaran-pai- berbasis.html. (Diakses 13 Juli 2018)

Goze Isno. "Pembelajaran PAI Berbasis ICT”, dalam http://isnoe82.blogspot.com. diakses 10 Desember 2011.

Hery Nugroho, Pembelajaran PAI Berbasis ICT dalam https://herynugrohoyes.wordpress.com/2012/08/11/pembelajaran-paiberbasi ict/(Diakses 13 Juli 2018

Nana Sudjana dan Ahmad Rivai, Teknologi Pengajaran Bandung: Sinar Baru, 1989

Rusman, dkk, Pembelajaran Berbasis Teknologi Informasi dan Komunikasi, Jakarta: Rajawali Pers, 2012

Rusman, Model-model Pembelajaran; Mengembangkan Profesionalisme Guru, (Jakarta: Raja Grafindo Persada, 2013

S. Nasution, Teknologi Pendidikan,Jakarta: Bumi Aksara, 2005.

Sudarwan Danim, Media Komunikasi Pendidikan: Pelayanan Profesional Pembelajaran dan Mutu Hasil Belajar, Jakarta: Bumi Aksara, 1994

Udin Saefudin Sa'ud, Inovasi Pendidikan, Bandung: Alfabeta, 2008

Yusufhadi Miarso, Menyemai Benih Teknologi Pendidikan Jakarta: Kencana, 2007,

Yayu Susanti, Pembelajaran PAI Berbasis Internet dalam http://yayususanti.blogspot.com/2016/01/pembelajaran-pai-berbasisinternet_17.html. (Diakses 13 Juli 2018) 